\title{
Educar para Comprender y Poder Cambiar la Ciudad
}

\author{
Educating for Understanding and Be Able to Change the City
}

Educar para a Compreensão e Poder Mudar de Cidade

\author{
Irene Quintáns ${ }^{1 *}$ \\ Alexandre Pelegi ${ }^{2}$
}

${ }^{1}$ Ocara Urbana. ${ }^{2}$ Associação Nacional dos Transportes Públicos

\begin{abstract}
El artículo discute las limitaciones y desafíos de lo que se ha convenido en denominar "Educación para el tráfico" en Brasil, tomando como base experiencias realizadas con niños en edad escolar de la periferia de São Paulo (especialmente Enseñanza Fundamental, de edades entre 6 y 14 años). Apuntamos cómo la educación centrada en la inseguridad viaria es practicada en Brasil y cómo las políticas públicas no acompañaron, hasta hoy, los avances observados en la legislación. Pretendemos demostrar que al revés que "educar para el tráfico” es preciso educar a los niños para comprender la ciudad en la que viven, utilizando herramientas lúdicas como, por ejemplo, talleres críticos y propositivos realizados en los colegios o, preferentemente, en espacios públicos.
\end{abstract}

Descriptores: Seguridad, Tráfico, Zona urbana, Política educacional, Juego.

The article discusses the limitations and challenges of what has been agreed to denominate "Education for traffic" in Brazil, based on experiences with children of school age in the periphery of São Paulo (especially Basic Education, aged 6 and 14 years). We point out how education focused on road insecurity is practiced in Brazil and how public policies have not accompanied, until now, the progress observed in the legislation. We pretend to show that, unlike "educating for traffic", it is necessary to educate the children to understand the city in which they live, using playful tools such as, for example, critical and purposeful workshops held in schools or, preferably, in public spaces.

Keywords: Safety, Traffic, Urban areas, Educational policy, Play.

$\mathrm{O}$ artigo discute as limitações e desafios do que se convencionou chamar no Brasil de "Educação para o trânsito", com base em experiências realizadas com crianças em idade escolar na periferia de São Paulo (especialmente de Educação Fundamental, com idades entre 6 e 14 anos). Apontamos como a educação focada em evitar os danos da insegurança viária é praticada no Brasil e como as políticas públicas não acompanharam, até hoje, os significativos avanços observados na legislação de trânsito. Pretende-se demonstrar que, ao invés de "educar para o trânsito", deve-se educar as crianças a compreender a cidade em que vivem, utilizando ferramentas lúdicas como, por exemplo, oficinas críticas e propositivas nas escolas ou, preferencialmente, em espaços públicos.

Palavras-chave: Segurança, Trânsito, Zona urbana, Política educacional, Jogo.

*Contacto: parahabi@gmail.com

ISSN: 2254-3139

www.rinace.net/riejs/

revistas.uam.es/riejs
Recibido: $\quad 15$ de noviembre 2016

$1^{\text {a }}$ Evaluación: 13 de enero 2017

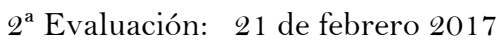

Aceptado: $\quad 20$ de marzo 2017 


\section{Introducción}

El objetivo del presente artículo es demostrar que cualquier acción educativa que busque una mejor relación del niño con su ciudad (en el entorno de su casa y colegio, así como otros espacios urbanos) no debe nacer de lo que se estableció en Brasil como Educación para el tráfico (educación en seguridad vial, en España) sí de una comprensión crítica y creativa del mundo en donde los niños conviven. Partimos del principio de los niños son las principales víctimas de una ciudad que no las acepta. Entonces, sólo habrá dos opciones: aceptar y resignarse o rebelarse y cuestionar. En el primer caso se trata de "domar" las mentes infantiles. En el segundo, educarlas.

El contexto de este texto es Brasil. Un país de dimensiones y realidades contrastantes, donde cualquier análisis relativo al tráfico y urbanismo necesita ser contextualizado, corriendo el riesgo de pecar gravemente en generalizaciones. La cuestión de la violencia provocada por el tráfico en las ciudades brasileñas (con todas sus externalidades negativas) impacta de forma muy específica y diversa a los niños y jóvenes en edad escolar. Los números asustan y provocan un fuerte aumento en la sensación de seguridad, lo que ha ocasionado alteraciones significativas en la elección de los modos de transporte, reduciendo los modos activos de movilidad en beneficio de los modos motorizados.

El número de muertes provocadas por el tráfico en las grandes ciudades del país, según datos del Ministerio de Saúde Brasil (2014), referentes al año 2013, confirman la gravedad del panorama. La ciudad de Sao Paulo, la mayor del país, tiene 10,35 óbitos/100.000 habitantes. A pesar del dato, los números de Sao Paulo están entre los mejores del país.

La violencia del tráfico tal vez sea la explicación más utilizada para explicar el alejamiento de los niños de las vivencias al aire libre y justificar su confinamiento en el transporte para el colegio dentro de vehículos privados (transporte escolar privado y coches particulares). Nosotros no estamos de acuerdo con esta relación causa-efecto, pues desde nuestro punto de vista el dato de los accidentes no es la principal causa de todo. Al contrario, es una consecuencia natural de un modelo de ciudad y los accidentes deben ser colocados en su debido lugar.

Empecemos estudiando cómo se conforma la relación de las personas (muy particularmente los niños) con la ciudad. Una serie de condiciones sociales, culturales, económicas y urbanas de las ciudades han hecho que la infancia sea, cada vez más, privada del contacto con el espacio público. Como consecuencia, además de los dramáticos daños para la salud infantil (sedentarismo, sobrepeso y diabetes, diagnósticos de trastornos de comportamiento y consecuente medicalización) incide en el desarrollo personal: la ausencia de contacto con los espacios públicos (o el "no vivir" la ciudad) provoca en los niños una sensación creciente de no pertenencia.

Rubem Alves (2009), educador brasileño, define bien lo que queremos mostrar aquí: "Aprendizaje es aquello que queda después de que el olvido haga su trabajo". Así, educar será construir con los niños ideas y conceptos que serán parte de su vida, que los harán ciudadanos capaces de utilizar lo aprendido como instrumento de transformación, no sólo de su existencia, también del mundo que le rodea. Esto es el concepto-clave con el que trabajaremos. 


\section{Fundamentación teórica}

\subsection{Educación para el tráfico: ¿Qué es?}

En Brasil, lo que hoy es asumido por los organismos oficiales como educación para el tráfico en el ambiente escolar, parte del principio básico de que los niños necesitan comprender las señales y los peligros del tráfico, con el objetivo de entender los procedimientos que precisan adoptar para caminar de forma segura en las calles de su barrio. De salida es una visión que coloca a los niños como propensos al error: si no son cohibidos (y educados), se colocarán a sí mismos en riesgo permanentemente. De esta forma, es necesario instruirlos, pues los niños son sinónimo de inocencia, del futuro adulto que necesita ser formado para vivir según las reglas sociales vigentes (reglas que no deben ser cuestionadas).

Todas las informaciones que componen esa educación no se basan en la perspectiva del niño, ni en cómo percibe la ciudad donde habita, se basan en la visión de los conductores de vehículos, vistos como monstruos contra los cuales los niños necesitan protegerse y aprender a convivir con ellos. Un ejemplo típico y hasta el día de hoy bastante popular en Brasil, son las ciudades en miniatura, que se expanden por varias ciudades del país, como estímulo y patrocinio de muchos organismos oficiales de tráfico. Su función principal es educar futuros conductores, con la trágica idea de los niños, potenciales víctimas, podrán ser profesores eventuales, llevando el buen ejemplo a sus padres y a sus familias, en una inversión absurda de valores.

Es por esto que, en Brasil, enseñar seguridad vial a los niños es la esencia de cualquier educación que busca reducir la letalidad del tráfico. Pero al mismo tiempo esta educación ignora las principales medidas para disminuir accidentes, basadas en evidencias internacionales: consumo de alcohol, reducción de velocidades, uso de caso y cinto de seguridad -incluido el banco posterior-, etc.

Esta visión parte del principio de que la ciudad ya está lista, de que es un universo dado, contra el cual no se puede ni se debe luchar. Lo que es necesario y suficiente, según reafirma este modelo, es educar a los niños para que se puedan enfrentar las diversidades y peligros que tienen las ciudades, como cruzar la calle, observar el semáforo, aprender las reglas de tráfico, Modelos educativos basados en este concepto no discuten porqué la ciudad y el tráfico son así. La ciudad, así como el uso de los espacios públicos y la forma de distribución de los modos de transporte en el viario urbano, más que cuestiones indiscutibles podrían ser el punto central de aprendizaje: se trata, por tanto, de domar a los niños para una realidad inmutable y aún más allá, replicar un concepto con la finalidad objetiva de eternizarlo. Los verdaderos factores que provocan muertes y secuelas en el tráfico son dados como efectos colaterales, es decir, no sería posible evitarlos (o mitigarlos).

¿Cómo invertimos esta tendencia? ¿Cómo cuestionar este modelo, que tiene fuertes determinantes económicos? Se trata de discutir, en última instancia, la desigualdad en la apropiación del espacio, de las riquezas y del poder.

\subsubsection{Nuestro recorte: cómo encarar el universo conocido por los niños en su camino al colegio}

El colegio es una parte indisociable del cotidiano infantil. Identificado como centro de una actividad cotidiana y repetida diariamente, el entorno por el que caminan, viven, experimentan sensaciones y miedos -por lo tanto, fuera del ambiente cerrado de la sala 
de aula- acaba impactando en sus percepciones. Por este motivo, el camino recorrido para llegar hasta el colegio es una actividad que puede educar y ayudar en la formación de los niños, de los amigos, de su familia e incluso de los vecinos del barrio.

En encuestas sobre la movilidad urbana infantil realizadas en colegios de barrios periféricos, Paraisópolis, investigación con 1.200 alumnos de 6 a 14 años y Jardim Ângela, investigación con 300 alumnos de 6 a 14 años (Quintáns, 2011,2015a), se puede observar el impacto causado por el entorno urbano y las percepciones que derivan de ello, también cómo eso se transforma en valores de definición de la práctica diaria de desplazamiento.

\section{El camino es largo, inseguro, fatigoso y desagradable. Me cansa y sudo por causa de las subidas y laderas. Pienso que la avenida (M'Boi Mirim) tiene malas aceras, es difícil saber cuándo se puede cruzar. Los coches van muy rápido, jhay mucha contaminación! Tengo miedo de que un coche me atropelle y de que alguien pueda hacer una maldad conmigo. Lo que más me gusta son los rayos de sol en el campo, escuchar el silencio, la calma, sentir el viento. (Gabriela, 10 años, Jardim Ângela)}

Los padres de muchos alumnos optan por el vehículo motorizado para sus hijos, principalmente el transporte escolar municipal o privado, debido a la inseguridad en el camino (tráfico intenso, aceras estrechas y de mala calidad, calles oscuras y mal iluminadas, altos índices de violencia).

En el documento "Estudio sobre caminos escolares de Jardim Ângela" en la periferia de la ciudad de Sao Paulo (Quintáns, 2015a), se obtuvo un dato sorprendente. El barrio había sido considerado en el año 1996, por la ONU, el más peligroso del mundo. Cuando los niños respondieron a la pregunta "Cuando caminas por las avenidas, ¿de qué tienes miedo?", el $80 \%$ de los alumnos de Enseñanza Fundamental I (6 a 10 años) que respondieron a la pregunta, escribieron "ser atropellado" (siendo el ítem "asalto" escogido por el $10 \%$ ). Otras preguntas mostraron la consciencia de los niños sobre la violencia del tráfico (figura 1). Se consideran las respuestas escritas, desconsiderando las vacías.



Figura 1. Estudio sobre caminos escolares de Jardim Ângela "Cuando camino por las avenidas... ¿de qué tengo miedo?"

Fuente: Elaboración propia. 

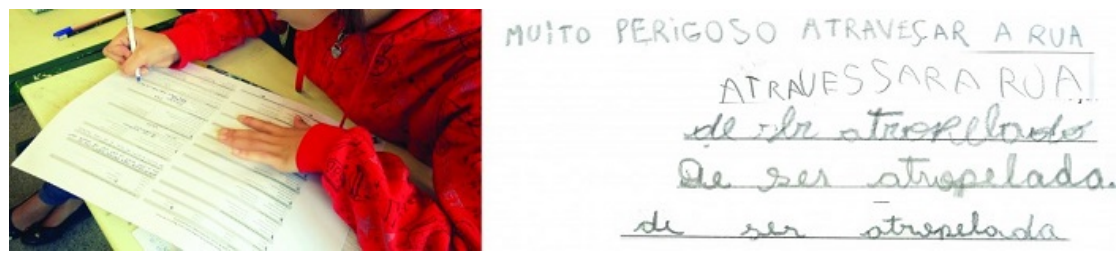

Figura 2. Alumno respondendo la encuesta, ejemplos de respuestas Fuente: Elaboración propia.

Lo curioso es que este "miedo" apuntado por los niños del barrio Jardim Ângela podría ser mitigado con políticas de ingeniería civil, soluciones técnicas (diseño de intersecciones, tiempos semafóricos, traffic calming, diseño y localización de pasos de cebra) y educación de tráfico para los adultos (figura 2).

A través de conversaciones con vecinos de Jardim Nakamura (alumnos y adultos), región circunscrita a Jardim Angela, se pudo constatar una percepcion territorial muy clara. Se verificaron territorios distintos dentro e un mismo espacio urbano:

- Los alumnos que viven "dentro" de Jardim Nakamura.

- Los alumnos que viven "después" de Jardim Nakamura (pero en el mismo lado de la avenida que el colegio).

- Los alumnos que viven "después de la avenida" (la vía interurbana M'Boi Mirim): para llegar hasta el colegio necesitan cruzarla.

Estos territorios y los datos de modos de transporte de los alumnos mostraron que la distancia casa-colegio no es el factor principal que define su transporte (figura 3). La inseguridad es la que define sus elecciones, expresada en el hecho de tener que cruzar la avenida, una infraestructura percibida como fuertemente insegura.

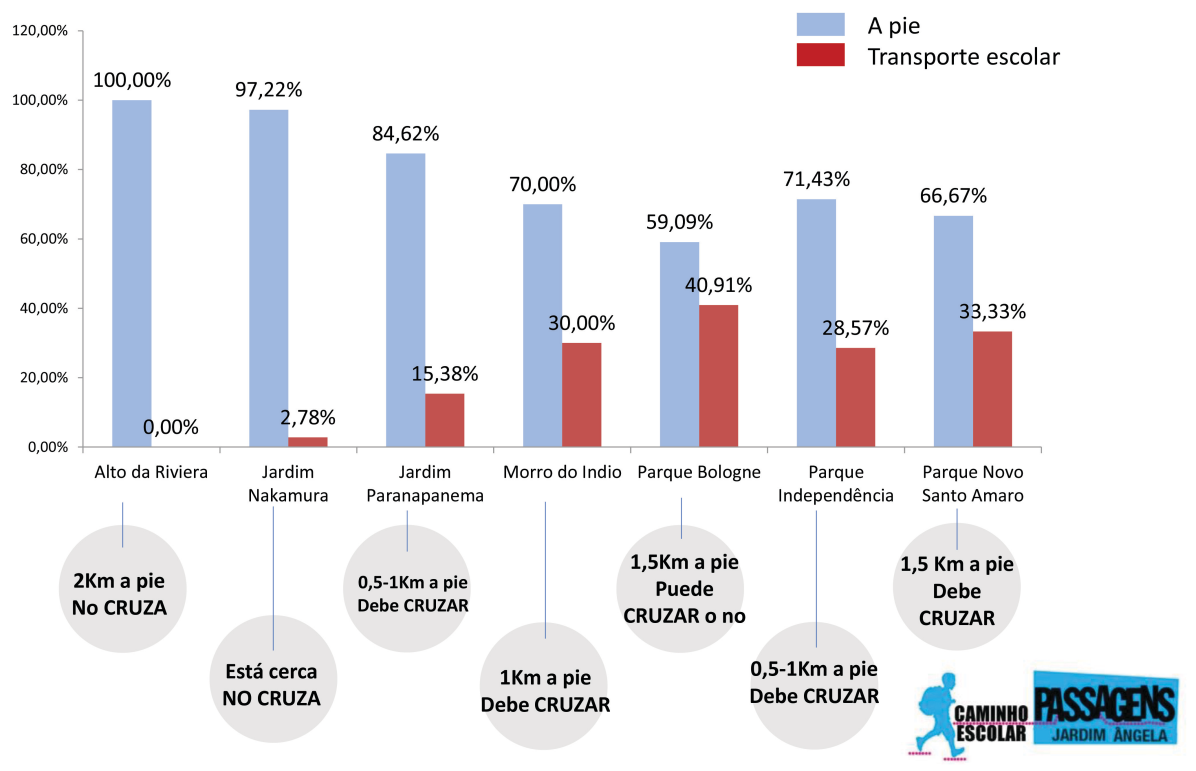

Figura 3. Modo de transporte hasta la escuela según barrio de residencia Fuente: Elaboración propia. 
En estudio realizado en Sao Miguel Paulista, otro barrio de la periferia paulistana, se analizó la Escuela Municipal de Enseñanza Fundamental Arquiteto Luís Saia (una muestra de 250 alumnos de 6 a 14 años, siendo 1.200 el alumnado total). El 39\% de los alumnos usan transporte escolar en sus desplazamientos casa-colegio, a pesar de que el $20 \%$ de ese grupo vive a una distancia de máximo $1 \mathrm{~km}$ lejos del colegio y el $56 \%$ hasta $2 \mathrm{~km}$ (figura 4). El porcentaje de uso transporte escolar aumenta cuando el alumno debe cruzar la avenida principal para llegar al colegio.

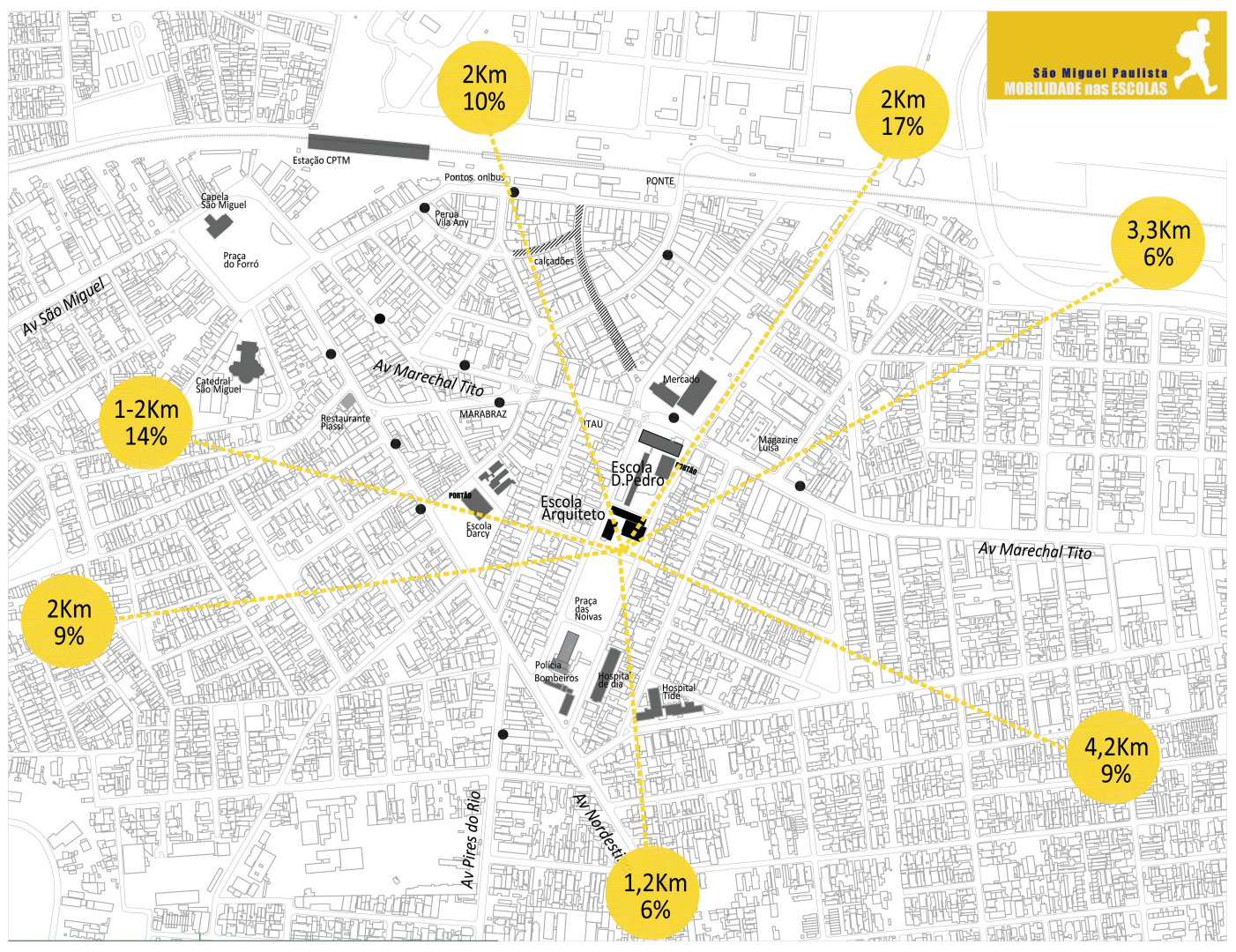

Figura 4. Mapa con los barrios de origen de los alumnos del colegio EMEF Arquiteto Luís Saia que usan transporte escolar (39\% sobre el total). Detalle: \% de alumnos que residen en cada barrio y distancia al centro escolar.

Fuente: Elaboración propia.

El barrio donde está situado el colegio (barrio Sao Miguel Paulista) es el tercer centro económico de la ciudad de Sao Paulo, pero al mismo tiempo es una de las áreas más peligrosas en lo que se refiere a seguridad vial. En 2014 la Avenida Marechal Tito, que cruza el distrito y está a pocos metros del colegio, registró el mayor número de accidentes fatales de la ciudad (figura 5).

A pesar de la diferencia con los datos obtenidos en los otros estudios de la Zona Sur de la ciudad, la criminalidad en Sao Miguel Paulista tiene un papel muy importante. De entre los problemas apuntados por los alumnos de dos colegios de Enseñanza Fundamental (la EMEF Arquiteto Luís Saia ya mencionada, y en otro colegio cercano, la EMEF Darcy Ribeiro) en su trayecto de ida y vuelta al colegio, esto quedó muy evidente. El recelo a ser asaltado y en segundo lugar el miedo a ser atropellado, caracterizó las respuestas sobre la percepción de inseguridad de los alumnos de edad entre 6 y 14 años al caminar por las calles. 


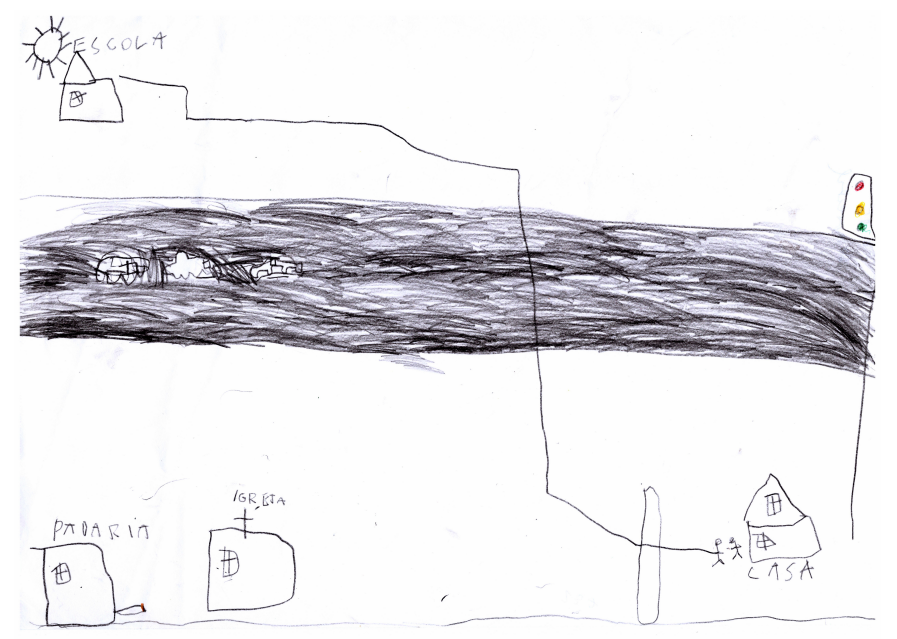

Figura 5. Dibujo de un alumno de 2 curso del ciclo Enseñanza Fundamental Fuente: Recuperado del estudio Movilidad en los colegios de Sao Miguel Paulista.

En el mismo barrio, Sao Miguel Paulista, se aplicó otra encuesta, en la Escuela estatal Dom Pedro I (alumnos de 14 a 17 años). Estos jóvenes estudian en tres periodos (mañana, tarde o nocturno). En este caso, el temor a ser asaltado alcanzó el $75 \%$ de las respuestas y la sensación más general de inseguridad apareció en el $27 \%$ de las respuestas. "Ser atropellado", un miedo presente en las EMEFS con razonables motivos, tuvo el mismo grado de respuestas que "asedio sexual" (tabla 1).

Tabla 1. Movilidad en los colegios de São Miguel Paulista

\begin{tabular}{lccccc}
\hline & $\begin{array}{c}\text { EMEF ARQ } \\
\text { LUIS SAIA }\end{array}$ & $\begin{array}{c}\text { EMEF } \\
\text { DARCY } \\
\text { RIBEIRO }\end{array}$ & $\begin{array}{c}\text { EE DOM } \\
\text { PEDRO I }\end{array}$ & TOTAL & $\begin{array}{c}\text { \% SOBRE } \\
\text { TOTAL }\end{array}$ \\
\hline $\begin{array}{l}\text { Ser assaltado } \\
\text { Ser atropelado }\end{array}$ & 23 & 32 & 50 & 105 & $53,3 \%$ \\
$\begin{array}{l}\text { Assédio sexual } \\
\text { Insegurança em }\end{array}$ & 11 & 22 & 7 & 40 & $20,3 \%$ \\
$\begin{array}{l}\text { geral } \\
\text { Escuridão }\end{array}$ & 5 & 3 & 7 & 15 & $7,6 \%$ \\
Total respostas & 2 & 10 & 18 & 34 & $17,3 \%$ \\
\hline Nota: Nún & 47 & 0 & 1 & 3 & $1,5 \%$ \\
\hline
\end{tabular}

Nota: Número de respuestas recibidas, por centro escolar, en la pregunta "Cuando caminas hasta la escuela, ¿tienes miedo de algo?”.

Fuente: Elaboración propia.

\subsubsection{El marco legal: ¿̨Producir leyes cambia la forma de construcción de la ciudad?}

A partir del Estatuto das Cidades (y la más reciente Lei de mobilidade urbana, promulgada en enero de 2012), Brasil pasó a cuestionar de una forma más contundente un modelo de ciudad que excluye a las personas y restringe su participación en la vida urbana. La importancia de este marco legal para el país fue celebrada por todos los técnicos y organizaciones de la sociedad que discuten el derecho de acceso a la ciudad y el uso del espacio público como premisa de inclusión social. Esta ley concedió prioridad a los medios de transporte no motorizados y al servicio público de transporte colectivo, incluyendo la posibilidad legal de aplicar restricciones al uso de automóviles. Fue la primera ley integral sobre este tema con una perspectiva de igualdad y sostenibilidad. Gracias a ello, puede asumirse que, por lo menos, el debate sobre estos temas estos 
esenciales empezó a plantearse más profundamente en los grandes centros urbanos. Pero esto aún es muy incipiente, restringido a grupos de activistas de las grandes ciudades y sin una expresiva repercusión social.

Los últimos 20 años, en verdad, fueron un rico periodo en el ámbito de la movilidad urbana en Brasil en lo que respecta a la legislación. La promulgación de una gran cantidad de leyes produjo un fuerte impacto en las condiciones reales de movilidad. Empezando con el Código de Trânsito Brasileiro (СТВ), que alteró profundamente la estructura de la organización institucional del área, principalmente por medio de la municipalización del tráfico, colocando a las autoridades locales en el centro del planeamiento y gestión de tráfico.

Hoy, gracias a eso, muchos temas son debatidos de una forma abierta en la prensa brasileña y en algunos fórums, como cámaras municipales de importantes ciudades del país. Podemos citar algunos de los principales temas: uso del espacio viario, prioridad para el transporte colectivo, prioridad y respeto a peatones y ciclistas, males producidos por el excesivo tiempo perdido en atascos provocados por el uso masivo de automóviles (y la contaminación ambiental derivada), situación del deterioro creciente de las aceras y la poca preocupación con los pasos de cebra, limitación de velocidades...entre otros.

El panorama es éste: Brasil avanzó en el marco legal pero poco en lo esencial, que sería producir políticas públicas definidoras de una nueva esencia de ciudad, pensada para las personas en lugar de los automóviles y de los intereses que históricamente representan y simbolizan. Sobre los niños y su relación con la ciudad, el tema (y lo más importante, lo que los niños piensan) permanece invisible en los debates, organismos oficiales que trabajan con movilidad urbana y entre los gestores públicos municipales. Como hemos explicado en el presente artículo, las autoridades de tráfico tratan a los niños como "seres incompletos o apenas en formación", "ciudadanos del mañana" (y no ciudadanos del presente). Lo que hacen, piensan y verbalizan hoy no es llevado en cuenta.

Si las leyes avanzaron en el país, cuando se trata del ambiente escolar este avance fue menor. Una cartilla del DENATRAN (2000), principal órgano responsable por el tráfico en Brasil, bajo el título "Señalización de áreas escolares", fue elaborada con el objetivo de estimular un trabajo junto a los colegios para "cualificar a los profesores en la transmisión a sus alumnos de los conceptos e instrumentos de ciudadanía y seguridad de tráfico".

El manual fue producido con la colaboración de una serie de entidades vinculadas al tráfico en el país y comprende una recopilación de los principales cuidados que deben ser tomados para garantizar mayor seguridad en el entorno de las áreas escolares. Curiosamente ninguna de las sugerencias de señalización y aumento de seguridad afecta a una mejor redistribución del espacio de la calle. El espacio destinado al coche es mantenido en todas las propuestas. Tampoco el manual presta una necesaria atención a las aceras. Las indicaciones que se hacen para aumentar la seguridad de los escolares contemplan pasos de cebra elevados, señales intermitentes, implantación de rejas para canalización de peatones, etc... Los niños continúan invisibles no sólo para las autoridades de tráfico, también para los gestores públicos. Son vistos como "aspirantes a adultos" que necesitan ser adecuados a la realidad preexistente donde el modelo de ciudad existente, además de mantenido y replicado, no es puesto en duda. 


\section{2. ¿Cómo enseñar a niños, la población más vulnerable de la ciudad?}

Pensar en áreas de seguridad escolar requiere una dimensión mayor que simplemente manuales técnicos y legislaciones específicas. Como ya explicamos, hubo en Brasil un significativo avance en los marcos legales, pero no en políticas públicas transformadoras. En el caso de los niños, mientras en países de varios continentes se abordaron los "caminos escolares" como proyectos integrales o incluso como políticas públicas municipales o nacionales, Brasil aún no consiguió avanzar en este debate.

Una de las principales premisas es que para prevenir y reducir de forma drástica los accidentes en el entorno de los colegios es necesario mucho más que proyectos técnicos de señalización, campañas que exijan respeto y atención de los conductores y peatones, o fiscalización intensiva y permanente. Creemos que es esencial la participación constante de padres, alumnos y profesores en las medidas básicas para reducir los principales factores causantes de accidentes de tráfico, como también la presión sobre las autoridades responsables para que participen decisivamente en el "rediseño urbano" que dé sentido y consecuencia a este esfuerzo.

\subsubsection{Enseñar ciudad en vez de tráfico}

Hemos intentando mostrar no sólo cómo la Educación dirigida al tema de la seguridad viaria se practica en Brasil, sino también demostrar cómo las políticas públicas no acompañaron a día de hoy los avances observados en la legislación sobre el tema. En referencia a los niños, particularmente los que están en edad escolar, observamos que muy poco o casi nada fue conquistado. Este escenario preocupante debe ser comprendido por quienes se dedican a esta área temática en el país y que creen que sus acciones ya están trayendo modificaciones sustantivas para la realidad urbana (figura 6).

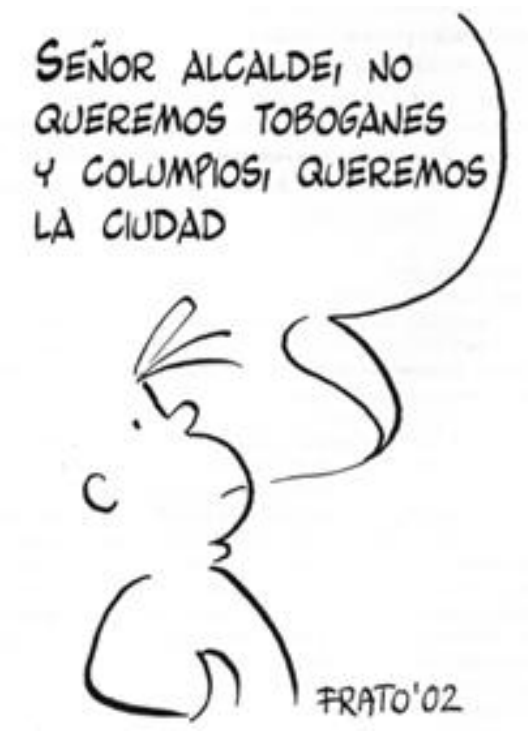

Figura 6. Dibujo de FRATO (acrónimo de Francesco Tonucci)

Fuente: Recuperado de Tonucci (2004, p. 237).

La ciudad debe ser diseñada y construida teniendo como marco esencial la seguridad de los niños y la liberación del mayor espacio posible para las personas. Una ciudad en la que los niños son expulsados de los espacios que deberían ser naturalmente suyos 
(espacios de convivencia y juego) es una ciudad excluyente, y es a partir de esta constatación que partimos como base para cualquier posibilidad de cambio.

Varios trabajos internacionales han contribuido a demostrar que eso es posible y esencial. El proyecto "La ciudad de los niños" del pedagogo italiano Francesco Tonucci es el único gran proyecto internacional de participación infantil donde se crean consejos de niños en diálogo con los ayuntamientos. Éstos asumen el compromiso de escuchar sus propuestas y ejecutar algunas de sus ideas. Empezó en Roma (años 90) y hoy tiene una gran red internacional en Italia, España y Latinoamérica. En Brasil se han localizado algunas experiencias que buscan inspirarse en esta propuesta de Tonucci, como es el caso de Santo André (ciudad de la Región Metropolitana de Sao Paulo), donde fueron creados los conselhos mirins (Prefeitura de Santo André, 2014).

Tonucci, a través de libros (2004) y charlas (1997 y 2012) defiende que:

$$
\begin{aligned}
& \text { el objetivo es poder crear un espacio nuevo que está desapareciendo, entre la casa y el } \\
& \text { colegio: la ciudad. Un lugar que en la actualidad no es usado, porque los niños van } \\
& \text { directamente de casa al colegio, o para otras actividades: aulas de danza, natación, } \\
& \text { inglés o volver a casa para ver la televisión. }
\end{aligned}
$$

Como observa Sanz (2009), "seguridad viaria es algo más que la simple inexistencia de accidentes”(p.7). Él defiende que observar exclusivamente los accidentes de tráfico nos impide ver la realidad compleja compuesta por la movilidad y por la habitabilidad, no nos deja comprender los fenómenos de riesgo. La movilidad motorizada como dado implícito incontestable nos impide apreciar los demás elementos de lo urbano: el espacio público, así, pierde sus múltiples facetas. La seguridad viaria, vista desde este ángulo, es algo mucho más complejo, pues trasciende los límites de las calles para sugerir un debate amplio sobre el concepto de ciudad.

La elección de actividades que coloquen a la ciudad como algo en permanente transformación y no como una construcción estática, debe ser el punto de partida de cualquier acción pedagógica que quiera abordar temas como la seguridad viaria y ocupación de los espacios urbanos.

Observamos que existen actividades que optan por aceptar la ciudad como ella es y, partiendo de esa concepción, sugieren formas de enseñar a los niños a adoptar posturas de mayor seguridad. Son las conocidas ciudades en miniatura, como el proyecto Cidade Portinho de São Paulo, modelos que quieren que el niño conozca el ambiente hostil de tráfico. Proponiendo que los niños jueguen de conductores y peatones sobre la visión de quien conduce un automóvil, esos juguetes quieren transmitir las principales informaciones sobre cómo comportarse bien en las calles y aceras de la ciudad. Resumiendo, sugieren que la obediencia a las leyes y reglas de tráfico son esenciales para reducir víctimas y la letalidad. Son formas de adiestramiento que no permiten cuestionar esa ciudad, negándoles, en esencia, el papel de agentes activos en las acciones. Se les trata como futuros conductores, en lugar de ciudadanos.

Desde la óptica de ciudad en mutación constante que defendemos, se define a priori cómo (y por qué) el entorno de los colegios impacta negativamente en los niños. Qué factores hacen que ellos (y sus padres y profesores) adopten posturas conformistas, que quieren preservar a los pequeños de un mundo exterior peligroso y, por lo tanto, prohibido (figura 7 ). 

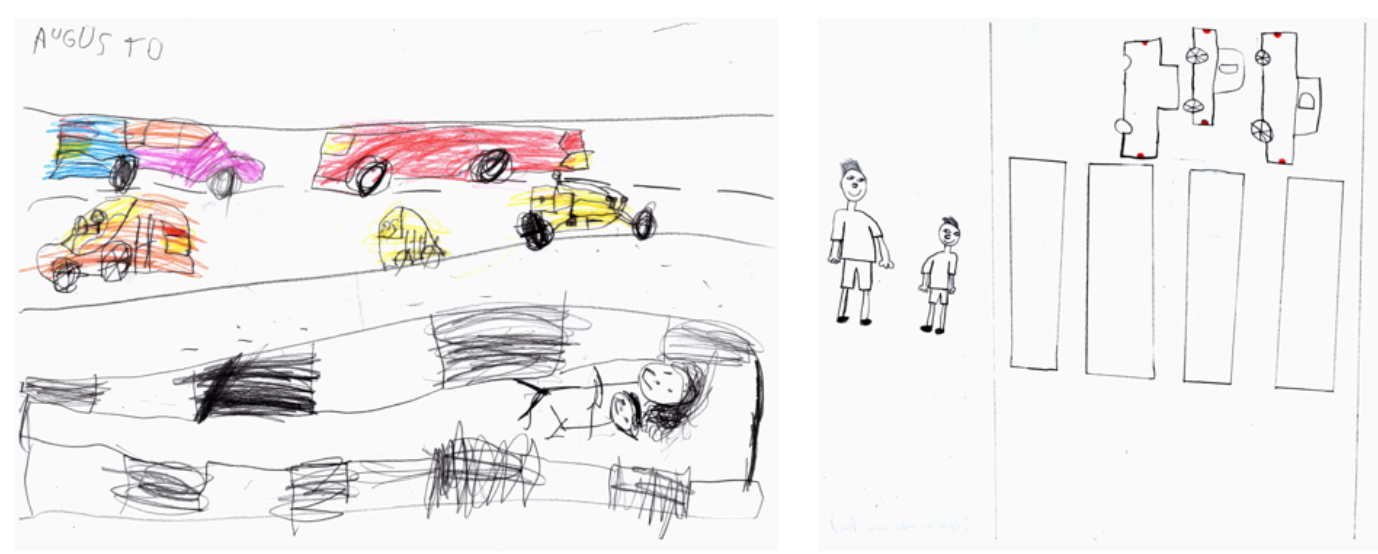

Figura 7. Dibujos de $1^{\circ}$ y $2^{\circ}$ curso

Fuente: Escuela Municipal de Enseñanza Fundamental Darcy Ribeiro (Sao Paulo, Brasil).

\subsubsection{Consecuencias de la exclusión de los niños del espacio público}

Una ciudad que se adecua al modo de transporte individual motorizado produce, como consecuencia natural y obvia, una serie de efectos colaterales, siendo los más visibles los que hoy aumentan las graves estadísticas de muertos y heridos, descritos de forma "pueril" por el nombre de "accidente". Los "accidentes" de tráfico serían, por tanto, algo casual fortuito, imprevisto, como enseña cualquier diccionario de lengua portuguesa; de esta forma fueron siempre justificados (y aun peor, aceptados) como daños colaterales por el progreso, otra palabra que nos remite a lo inevitable, algo determinado e imposible de ser detenido (al final, ;toda ciudad necesita avanzar!).

El cuestionamiento del uso del automóvil como modo de transporte ganó en los últimos años una faceta más visible $y$, por qué no decirlo, más humana: la destrucción de espacios públicos de convivencia. Como ya apuntaba Jane Jacobs (1969/2011) en su libro "Muerte y vida de las grandes ciudades", la hegemonía de los automóviles provoca erosión urbana. A partir de una realidad dada y aceptada, asumir como única verdad inmutable que la ciudad es peligrosa parece ser lo más común. Estas actitudes impuestas a la sociedad y reproducidas en los colegios públicos y en los programas oficiales de educación para el tráfico, conducen a consecuencias que generan miedo, como el no jugar, no caminar o no cuestionar.

Los hábitos derivados de toda esta situación parecen naturales, asumidos como la forma correcta de defender al niño de los peligros de la ciudad peligrosa. Contextualizando esto en Brasil y muchos otros países, hábitos como encerrar a los niños en casa con la televisión, con programas televisivos o video juegos, recluidos y controlados con actividades programadas y dirigidas, acaban siendo consecuencias de una postura de autodefensa familiar. Salir de casa sólo se permite a los niños si es para ir a otros lugares seguros y sin relación con espacios externos, como los centros comerciales. Los niños crecen dentro de una burbuja de protección excesiva en cuyo lado externo se encuentra la ciudad y sus peligros.

Pensamos diferente: es necesario incluir a los niños en la ciudad y la organización de las formas de desplazamiento de las personas, con una perspectiva de futuro, pensando la ciudad que sea buena para los niños y para todos. ¿Cómo hacerlo? 


\subsection{Incluir a los niños en la ciudad}

Las políticas públicas son evaluadas, normalmente, por medio de indicadores, metas, objetivos. Sin embargo, ¿podemos decir que las políticas contribuyen al desarrollo integral, saludable, seguro y estimulante de los niños? ¿Qué les transmite el espacio urbano? ¿Cómo uno conforma al otro? Las políticas públicas, como decisiones aisladas, no pueden responder a estas preguntas.

Pernas y Román (2015) traen una reflexión sobre el significado de la palabra cuidar: "procede del latín cogitare, pensar. El cuidado está vinculado al hecho de contemplar e integrar las necesidades de otros dentro de las propias atribuciones y prioridades. De este modo, podemos plantear que una ciudad que cuida es aquella que destina tiempo, energía y recursos a pensar, precisamente para incluir en sus actuaciones las complejas y variadas necesidades de la ciudadanía y, especialmente de quienes más cuidado precisan”.

El libro "Child-friendly community indicators. A literature review" de Woolcock y Steele (2008) indica algunos caminos para analizar las agendas urbanas. Sistemáticamente las diferentes agendas coinciden en buscar 1) la reconexión de los niños con los paisajes donde viven 2) Revalorizar a los niños en sus entornos comunitarios y 3 ) reincorporar a los niños en los procesos democráticos civiles. Esto nos lleva a plantearnos dónde encaja el medio ambiente físico...

Sentir, tocar, disfrutar... ¡apropiarse del espacio urbano!

Los adultos adoramos hacer eso en la playa, en la hierba del parque, en un pic-nic, en un terraza de madera, en la escalinata de una plaza. Pero el resto del día, preferimos otra mirada y olvidarnos de lo que pisamos. "Pisamos". Nuestro nivel cero de la ciudad no es un espacio vivido, es un espacio pisado. Para los niños es más fácil una cuestión de escalas, ipues ellos están cerca del suelo! pero nosotros, adultos, tenemos nuestra vista a más de un metro del suelo.

Nuestros hábitos de movilidad urbana aún separan nuestros pies más centímetros sobre el suelo: nuestros pies no sienten la ciudad, están elevados medio metro (o más). $\Upsilon$ nuestros niños son transportados así, sin tocar el suelo. Perdieron su espacio de libertad: sentir, tocar, disfrutar. Porque si no les dejan en la arena del parque, ¡mucho menos en la acera! Aun así, si caminamos con un niño por los lugares que conocemos, probablemente nos sorprenderemos. ¡Porque ellos se fijan en todo! $\Upsilon$ lo que está más cerca del suelo, lo que no vemos, es, a veces, para admirar y observar. (Quintáns, 2015b, p. 1)

¿Pero...esto será verdad, existen sutilezas en los espacios urbanos?

Si nos fijamos en muchas calles de las ciudades brasileñas vemos elementos innecesarios que bloquean cualquier opción de sentarnos o apoyarnos. Bolas u otros elementos poco amigables, plantas con espinas. Si los adultos ya estamos acostumbrados, imaginemos cómo un niño, desde su altura, percibe eso. Entonces, ¿habrá posibilidad de sentir sutilezas? (Quintáns, 2016a):

Cuando voy para el colegio, caminando con mi madre y mi hermano, es genial, nos reímos y hablamos. Me encontré con un amigo en el camino, que me prestó su juguete. Una mujer que paseaba a sus perros me miró y sonrió, le di los buenos días. Mi hermano, sentando en su carrito de paseo, jdijo que vio una hormiga gigante! Recogí una flor hermosa del suelo y se la di a mi madre, que se la colocó en el cabello. Vi un automóvil aparcado en la vereda, ¡no me gustó, era mi espacio! 
$A$ veces mi madre pregunta cosas extrañas. Hoy me preguntó si yo sabía por qué no hay bancos para sentarse. ¡Creo que se olvidaron de ponerlos! (Guillerme Q. Cunha, 5 años, São Paulo)

Pues sí, cuando los adultos damos el tiempo y espacio que los niños necesitan, ven todo eso. Caminar con ellos tendría que ser un derecho en nuestras ciudades.

\section{Talleres e intervenciones. Lo lúdico como herramienta del pensar}

Sería casi natural afirmar que todos los niños deben ser enseñados sobre qué hacer para evitar (o minimizar) los riesgos existentes en las calles por donde caminan. Es una forma de preservar su vida, su integridad. Pero la esencia de eso ellos ya la saben, a pesar de muchos vicios heredados de sus padres u otros adultos que, desde temprano, les "enseñan" a burlar las reglas de tráfico: cruzar fuera del paso de cebra para ganar tiempo, no esperar los largos tiempos semafóricos para cruzar la calle, utilizar el breve intervalo en el que no pasan coches (ya que ellos no paran) en los cruces de calles sin semáforos: muchas actitudes que en vez de educar, confunden a los niños.

Enseñar seguridad vial, de esta forma, debe partir de las preguntas que los niños podrían formular con nuestro estímulo: ¿Por qué no puedo ir en bicicleta? ¿Por qué no puedo jugar en la calle? ¿Por qué no puedo ir caminando a mi colegio?

Un taller libre en el espacio público es un buen antídoto para des-construir la falsa premisa de que las ciudades son locales prohibidos (ipues son peligrosos!) para los niños. Es una forma lúdica para que ellos comiencen a entender el mundo en el que viven, y a partir de ahí construir sus propias preguntas. Sus padres empiezan también a ver que jugar en los espacios públicos no es el monstruo que creían, pueden recordar cómo ellos disfrutaban hace no tantos años.

Si los niños preguntasen a sus padres descubrirán que ellos hacían todo eso (¡mucho!): iban en bicicleta, la calle era el lugar de encuentro y de diversión con los amigos, caminar era un acto natural y saludable. Sus padres conocían la ciudad, pues "vivían en ella” ... Ese contraste genera un ambiente de duda y es ahí donde debe nacer el estímulo para que los niños sean cuestionadores y curiosos. ¿Por qué mi calle tiene esta forma? Y más importante: ¿Podría ser diferente? Pues bien, podrán descubrir por ellos mismos que ¡sí!

Hablar sobre transporte activo para niños en un ambiente hostil es más que imprudente, es ineficaz. Explicar que debe cruzar por el paso de cebra (aun cuando a veces no existen), o que es necesario respetar el semáforo (aun cuando tarda mucho en ponerse verde) no es un gesto pedagógico, es algo que hace que los niños tiendan a conformarse con una realidad que se presenta como incuestionable. El transporte activo sólo es posible en ambientes no hostiles, en espacios públicos donde el derecho al uso de la calle es ejercido y supervisado por todos.

Indicadores de calidad, que definen qué es una ciudad para vivir bien, parten de una elección: ¿para quién debe ser destinada? ¿De qué forma debe ser diseñada y construida? ¿Cómo las personas se relacionarán entre sí a través de los espacios urbanos disponibles?

La utilización de talleres infantiles en las calles o plazas, así como la exhibición de videos que, de manera sutil, les haga reflexionar sobre la tragedia producida por el tráfico, son 
herramientas eficaces para ayudar a los niños a organizar sus dudas. A partir de ahí, buscar las mejores respuestas.

Colocar a los niños como hacedores de ciudad es el primer desafío, al mismo tiempo que es la base de todo. El compositor brasileño Caetono Veloso compuso en los años 70 una canción donde sus primeros versos enseñan: "Everybody knows that our cities / Were built to be destroyed". Es necesario mostrar a los niños la historia de su ciudad, cómo ella fue construida y destruida innumerables veces (y continuará siendo así). Más que eso: cuáles son los motivos que promueven esas mutaciones, a qué intereses responden, a qué grupos benefician. ¿Cuál es el modelo de ciudad que debería beneficiar el desarrollo saludable infantil? Esta es la pregunta que los niños podrían externalizar, buscar sus respuestas produce poderosos mecanismos de aprendizaje.

Haciendo su propia ciudad, su propia calle, su propio barrio, aun siendo de forma lúdica, jugando a hacer, todo eso hace que los niños descubran la ciudad que podría ser muy diferente a lo que está hecho. Y más aún, ellos ya presienten que quien hace la ciudad determina quién será beneficiando y quién perjudicado.

Lo que percibimos en las experiencias de los talleres para las escuelas de Enseñanza Fundamental en la periferia de Sao Paulo es que a través de lo lúdico y del juego es posible cambiar el enfoque de los niños sobre su relación con la ciudad. Lo que ellos percibían como natural pasó a ser, en un primer momento, cuestionado, para ser rechazado a continuación.

\subsection{Taller kit detector de obstáculos - descubriendo las aceras}

Pudimos observar esto en unas actividades realizadas con alumnos de 9 y 11 años en la calle de su colegio. Los estimulamos a auditar la situación de las aceras por donde ellos pasan todos los días, donde nunca habían percibido muchos detalles importantes (la mayoría de ellos perjudiciales para los niños, haciendo que su camino sea más peligroso y nada agradable): provocamos un inicio de reflexión. Lejos de aceptar los peligros físicos de las calles como naturales, pasaron a preguntarse por qué no podría ser diferente. Por ejemplo, ampliar las aceras y cuidar su mantenimiento (figura 8).

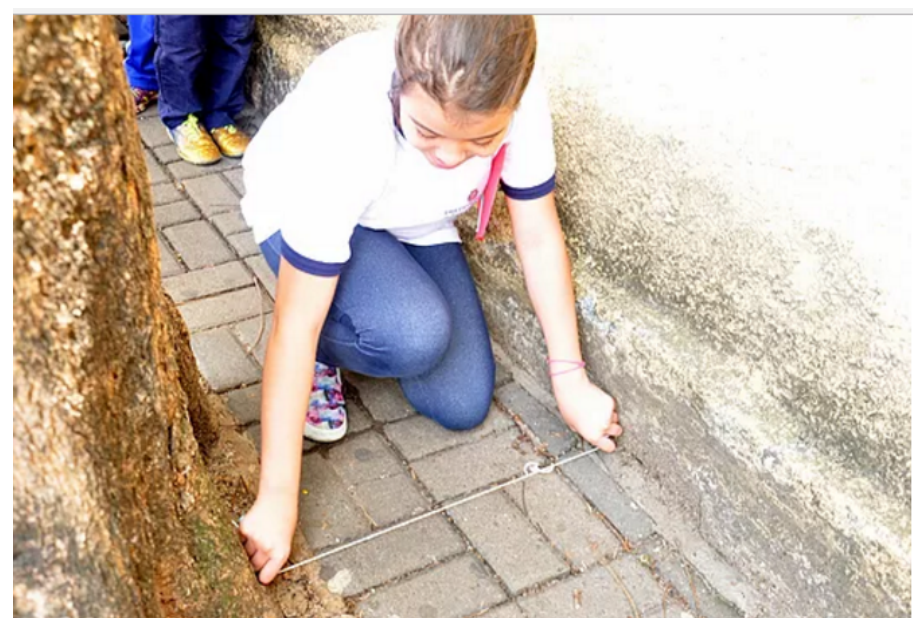

Figura 8. Alumnos usando el Kit detector de Obstáculos Fuente: Recuperado de Quintáns (2016). 
Las aceras son el ejemplo más claro de cómo el bien común se tornó privado desde la proliferación de automóviles en las ciudades. Lo que debería ser un bien cuidado por todos y para el uso de todos, se convirtió en propiedad de pocos en detrimento de la mayoría. Al final, ¿qué parámetros usamos para medir los espacios de las ciudades? La mentalidad que se percibe en las ciudades de Brasil aún es que es natural aceptar que las ruedas de los coches y sus velocidades es lo que irá a determinar los anchos y profundidades de los caminos a recorrer, en contraposición a los pies que todos usamos para caminar.

Verónica Mansilla, una arquitecta de Tucumán (Argentina), creó una forma simple y fácil de detectar obstáculos en las aceras. En una caja de fósforos vacía acondicionó un artefacto creativo, compuesto de un hilo, un pedazo de tiza y una tapa de botella de plástico. Lo nombró "Kit detector de obstáculos" (Mansilla, 2016). Con esta herramienta y orientados por sus profesores, los niños salen a la calle evaluando las condiciones de las aceras en sus caminos al colegio. Colocando la tapita en desniveles, los niños detectan obstáculos peligrosos para personas en sillas de ruedas o personas mayores. Con el hilo, que tiene una tiza colgada a los $75 \mathrm{~cm}$, se traza un círculo para descubrir si la persona en silla de ruedas consigue realizar un giro para volver a su camino sin la necesidad de salir de la acera. Y con el largo total del hilo se mide el ancho de las aceras, definidas con una dimensión mínima de $90 \mathrm{~cm}$ de ancho. Una práctica que une geografía, ciencias, matemáticas y ciudadanía.

Este kit fue utilizado en los talleres en Sao Miguel Paulista, en la EMEF Arquiteto Luis Saia, en la acera delante de su escuela. Los alumnos descubrieron que no sólo es peligrosa para tropezar, sino que también impide el paso de sillas de ruedas y para que los niños, así como sus padres, puedan realizar sus caminos tranquilos. Aprendieron, con una sencilla auditoría realizada con el Kit, que quien quiere caminar por la ciudad no tiene prioridad. Ni la atención de las autoridades, que debería cuidar la seguridad vial de todos.

Y aquí volvemos a la cuestión legal: una ley municipal, decretada y promulgada en 2007 en la ciudad de Sao Paulo, determina el área escolar segura, correspondiente a un radio de 100 metros, con centro en las puertas de entrada y salida del colegio. En este entorno, la ley decreta (entre muchas recomendaciones) que deberá ser hecho el mantenimiento de las aceras "para que queden en perfectas condiciones de uso". Si todos los niños de un barrio, o incluso de una ciudad, saliesen a las calles con este kit detector de obstáculos en el entorno de sus colegios y realizasen la auditoría de calidad de los caminos que recorren todos los días, los alcaldes tendrían un mapa real y sincero de los daños que la ineficiencia produce en la vida de las personas: de los padres, de sus hijos y de todos los caminantes de la ciudad.

\subsection{Taller curitas urbanas (Curativos urbanos)}

De las curitas que colocamos aun creo que fueron pocas, pues hay mucho que debe ser mejorado. No nos deberíamos resignar con lo que está aconteciendo pues somos ciudadanos y merecemos mejorías. Entre las reformas que deben ser hechas están: recoger la basura de las calles, colocar contenedores ecológicos, arreglar el paso de cebra y señales de tráfico, tener más señales en las calles. Algunas obras que "ellos" hicieron están muy mal ejecutadas, creo que deberían arreglarlas. (Kethlyn Alessandra, $8^{\text {a }}$ - Jardim Ângela, Sao Paulo)

Esta opinión refleja parcialmente el diagnóstico realizado por alumnos del barrio Jardim Angela en la peligrosa via Estrada M'Boi Mirim. En el estudio realizado en el barrio 
(Quintáns, 2015a) se verificó, como ya se ha comentado, que el factor que define el modo de transporte de los escolares es la inseguridad (y no la distancia hasta el colegio).

La actividad se realizó con los alumnos de $8^{\mathrm{a}}$ serie de la Escuela Estatal Oscar Rodrigues Alves (13 años de edad) en el barrio Jardim Ângela (São Paulo). En la misma escuela estaba siendo estudiado el trayecto casa-colegio de los alumnos, para el proyecto internacional Passagens, del Instituto Ciudad en Movimiento. Las curitas urbanas no sólo funcionaron para sanar las calles del barrio (Bela Rúa, 2012). En nuestra conversación previa con los jóvenes, también sanamos algunas preocupaciones: ellos tienen que lidiar con los prejuicios y la falta de oportunidades, por haber nacido allí, pero no son menos que nadie. Merecen lo mejor y las curitas fueron colocadas con una visión muy crítica y proactiva. El derecho a la ciudad está ahí.

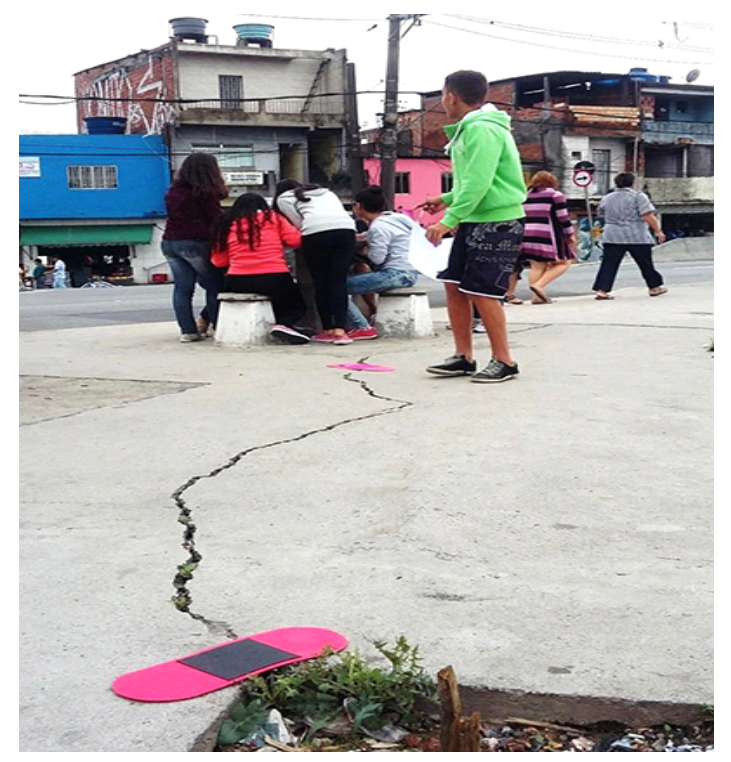

Figura 9. Alumnos usando las Curitas urbanas Fuente: Elaborado a partir de Quintáns (2015).

\begin{abstract}
Me gustaría que los policías nos prestasen más atención para poder reducir el número de acidentes. También me gustaría que la duración del verde del semáforo de peatones fuese mayor. (Jenyffer, 8 a série - Jardim Ângela)
\end{abstract}

\title{
2.3. Taller habitantes de la ciudad. Una ciudad ideal es aquella donde podemos jugar sin miedo
}

En otra actividad realizada con niños de 3er curso de Enseñanza Fundamental (9 años de edad), denominada Habitantes de la ciudad, partimos de la premisa de que la ciudad es de las personas. Sentados en un círculo en el suelo de la plaza pública anexa al colegio (EMEF-Arquiteto Luis Saia), sugerimos que los niños hablasen sobre el significado de la palabra "ciudad" para cada uno de ellos: de la existencia de espacios para el juego, de los miedos que las calles y los caminos esconden, de los motivos por los que no se camina ni se juega fuera de casa. Después de esta conversación, diseñamos una ciudad más humana usando papel craft en el suelo, con colores. Los niños hacían siluetas de sí mismas y de sus amigos, sin los miedos que la ciudad trae. Colgamos los dibujos entre los árboles para posteriormente, dentro de la sala de aula, hiciesen otros dibujos con las reflexiones sobre la actividad (figura 10). 


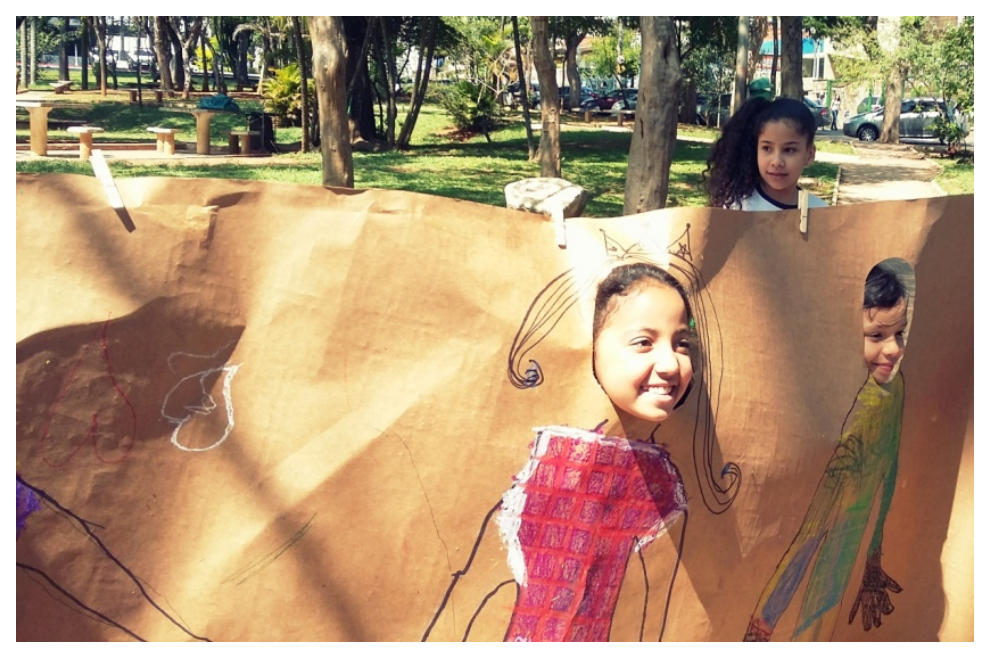

Figura 10. Taller "Habitantes de la ciudad" Fuente: Elaborado a partir de Quintáns (2016).

\subsection{Taller calles completas. La calle es de todos, ¿pero todos pueden usarla como quieren?}

Realizamos este taller en dos salas de aula (una con niños de 6 años y otra de 10 años), en la EMEF Darcy Ribeiro. La actividad tuvo como objetivo hacer que los niños percibiesen cómo las calles son utilizadas para poder concluir cómo el espacio urbano está mal distribuido, con predominio de coches en lugar de las personas. De forma progresiva, partiendo de una calle dibujada en un panel, los niños fueron describiendo su percepción sobre qué había en las calles. En su barrio había coches, motos, autobuses, bicicletas y las aceras tenían menos o más espacio para los peatones. A partir de ahí se fueron incluyendo ítems complementares, que no siempre se perciben: pasos de cebra, aceras rebajadas para sillas de rueda, ancho de las aceras y obstáculos para caminar (figura 11).

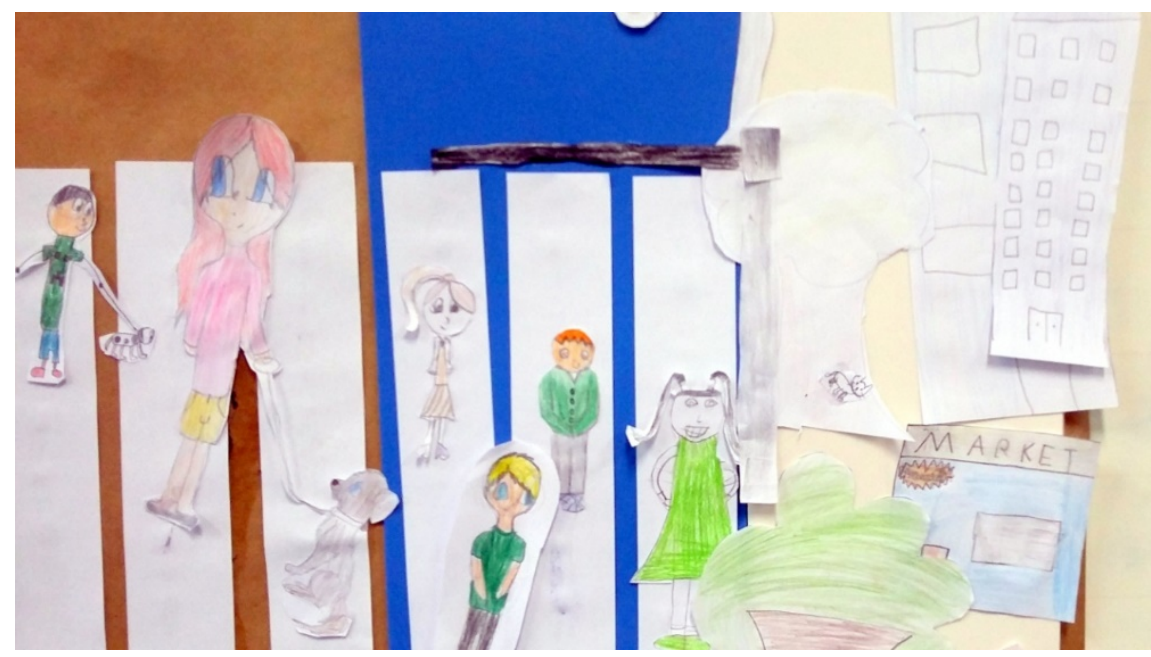

Figura 11. Taller "Calles completas"

Fuente: Elaborado a partir de Pelegi (2016).

A través de las actividades lúdicas, como dibujar y pegar, los niños comprendieron que es posible redistribuir el espacio, con el resultado de una convivencia más justa entre 
todos los modos de transporte. Principalmente para el peatón, que necesita más atención y cuidado.

\section{Algunas reflexiones finales}

Sentados en una plaza de la ciudad, hablamos con los niños sobre el sentido del hábitat urbano y qué significa ser un habitante. Niños de nueve y diez años estaban abiertos a entender qué significa cuidar de la ciudad: usar la ciudad, vivir la ciudad. La calle, la plaza, la ciudad, todo es nuestra casa, como un juego de muñecas rusas Matryoshka.

La ciudad es el trabajo colectivo en el que todos participamos. ¿Por qué concluir estudios técnicos, académicos y proyectos con talleres? Porque los vemos como un campo de test. Nos muestran claramente los conceptos que necesitan ser trabajados con los niños para que ellos se tornen ciudadanos con capacidad de empatía y cambio. Experiencias como esas, incluyendo a niños y sus centros escolares, una vez procesadas y sistematizadas, son una base sólida para adoptar políticas públicas para pensar y hacer ciudad incluyendo la óptica, percepciones y necesidades infantiles. Nos parece claro que acciones educativas pueden mejorar la relación del niño con su ciudad, pero para eso tales acciones deben nacer de una comprensión crítica y creativa del mundo en el que vive. Una ciudad en la que los niños son expulsados de los espacios que deberían ser naturalmente suyos (espacios para convivir y jugar) es una ciudad enferma.

Un niño debe ser visto y asumido como agente social de cambio, no como víctima de una ciudad hostil y peligrosa. Él puede cambiar la relación de las personas con los espacios públicos, humanizándolos y transformándolos en locales de inclusión y crecimiento. La tarea de la humanización de la ciudad es un delicado bordado de conceptos de humanidad, ciudadanía, de intercambio, fraternidad, paz, respeto a la pluralidad, cultura de redes de colaboración con la democracia (Mansilla, Quintáns, Almeida, 2016).

Como afirmamos en este artículo, el modelo oficial de educación basado casi exclusivamente en las reglas de tráfico es equivocado y revela una tendencia reinante en Brasil desde hace décadas: mantener sin cuestionamientos una ciudad excluyente. Es necesario discutir la ciudad y las formas de desplazamiento de las personas de una forma que anime a los niños a construir, empezando en primer lugar por la imaginación y la producción de referencias espaciales: la ciudad que les gustaría tener para ellos y sus hermanos. Un modelo educativo que aparte las certezas y privilegie las preguntas: cpor qué es necesario "convivir" o "respetar" a los coches? ¿Por qué nuestras casas están muy lejos de los locales de trabajo y del colegio? ¿Por qué la calle es peligrosa para quien quiere (o necesita) caminar o pedalear su bicicleta?

¿Qué inspira a nuestros niños? Seguramente un nuevo modelo de ciudad que, evidentemente, gestará un modelo de sociedad fundado en nuevas formas de convivencia, nuevos hábitos de consumo, teniendo varios temas como base: el medio ambiente pero también la economía colaborativa, la lucha contra el desperdicio, intentar mejorar lo existente en vez de producir nuevas existencias. Esto apuntaría para un modelo de economía resultante de una nueva generación que busca en todo el planeta modelos de ciudades volcadas en las personas (Pelegi, 2016). La sociedad cambiante cambia sus hábitos, y los nuevos hábitos traen más cambios. 


\section{Referencias}

Alves, R. (septiembre, 2009). A máquina de fazer salsichas. Recuperado de http://www 1.folha.uol.com.br/fsp/cotidian/ff2909200903.htm

Bela Rúa. (2012). Curativos urbanos. OCARA Lab. Recuperado de http://www.redocara.com/proba-ocara-lab

Ministério da Saúde Brasil. (2014). DataSus CID. Acidentes de transportes terrestres referentes ao ano 2013. Recuperado de http://tabnet.datasus.gov.br/cgi/deftohtm.exe?sim/cnv/ext10uf.def

DENATRAN. (2000). Sinalização de áreas escolares. Brasilia: Denatran.

Jacobs, J. (2011). Muerte y vida de las grandes ciudades. Madrid: Capitan Swing.

Mansilla, V. (2016). Kit detector de obstáculos. Recuperado de http://www.redocara.com/propuesta-2-ocara-lab-argentina

Mansilla, V., Quintáns, I. y Almeida, F. (2016). Rosario de O a 3. Revista dos Transportes Públicos, 143 , art. 3.

Pelegi, A. (2016). Bom conselho. Revista dos Transportes Públicos, 142, art. 6.

Pernas, B. y Román, M. (2015). Ciudades cuidadoras, ciudades cuidadas. Recuperado de http://www.galde.eu/ciudades-cuidadoras-ciudades-cuidadas/

Prefeitura de Santo André. (2014). Conselhos mirims. Recuperado de http://portal.aprendiz.uol.com.br/2014/06/27/em-santo-andre-criancas-ajudam-adefinir-politicas-publicas-e-orcamento/

Quintáns, I. (2013). Caminho escolar de paraisópolis 2011-2013. Recuperado de http://www.cidadeemmovimento.org/premiomobilidademinuto/iniciativa/ffac23bf631a2 244f79041107b496c3b

Quintáns, I. (2015a). Estudo sobre os caminhos escolares de Jardim Ângela. Recuperado de http:/ / cidadeemmovimento.org/com-trabalho-piloto-ivm-promove-estudos-paramelhorar-passagens-do-jardim-angela/

Quintáns, I. (2015b). Você pisa ou caminha? Recuperado de http://www.mobilize.org.br/blogs/passos-e-espacos/vocepisaoucaminha/

Quintáns, I. (2016a). Há leveza. Blog passos e espaços. Recuperado de http://www.mobilize.org.br/blogs/passos-e-espacos/haleveza/

Quintáns, I. (2016b). Redes internacionales: ¿Cómo incluir en ellas la ciudad e infancia? Revista Medio Ambiente y Urbanización, 84, 181-202.

Sanz, A. (2009). Interventions to increase traffic safety, overview of local policies. Recuperado de http://www.aeneasproject.eu/docs/2th_workshop_donostia/AENEAS_WS_Alfonso_SANZ.pdf

Tonucci, F. (1997). Charlas sobre la ciudad de los niños. Congreso internacional de educación católica, Buenos Aires. Recuperado de https://www.youtube.com/watch?v=l-xqruivlJU

Tonucci, F. (2004). Cuando los niños dicen ¡BASTA! Salamanca: Fundación Germán Sanchez Ruiperez.

Tonucci, F. (2012). Charlas con el consejo de niños de la ciudad de Rosario, Argentina. Recuperado de https://www.youtube.com/watch?v=-ikSvWLcXCE

Woolcock, G. y Steele, W. (2008). Child-friendly community indicators. A literature review. Recuperado de: http://www.childhealthresearch.eu/ 


\section{Breve CV de los autores}

\section{Irene Quintáns}

Arquitecta (ETSAC, 2005). Máster Profesional de Estudios Territoriales y Urbanísticos (UPC-UPF-EAPC, 2008). Ha trabajado para el Ayuntamiento de Barcelona (ProEixample S.A.) y Prefeitura de São Paulo - Brasil, en la Secretaría Municipal de Vivienda (SEHAB), donde participó en el Programa de Urbanización de la Segunda mayor favela de la ciudad (Paraisópolis). El Programa recibió el premio Scroll of Honour de UN-HABITAT (2012). Actualmente es consultora de proyectos y políticas públicas urbanas. ORCID ID: 0000-0003-3467-7661. Email: redocara@gmail.com

\section{Alexandre Pelegi}

Matemático (1988), brasileño, nacido en 1955. En la actualidad es consultor en el área de la movilidad urbana en ANTP - Asociación Nacional de Transporte Público, organización civil sin ánimo de lucro fundada en 1977. Es el editor de la Revista dos Transportes Públicos, principal publicación principal especializada en el transporte en el país, fundada en 1978. Desde los 80 actúa directamente sobre el área de transporte público, a través de diversos organismos gubernamentales. ORCID ID: 0000-00028985-6723. Email: pelegi@icloud.com 